\title{
PERBAIKAN MANAJEMEN PEMASARAN TERHADAP PENINGKATAN OMSET PRODUK TENUN SONGKET PALEMBANG
}

\author{
Muhammad Zaman $^{1)}$, Sony Oktapriandi' ${ }^{2}$, Nelly Masnila ${ }^{3)}$ \\ ${ }^{1}$ Teknik Kimia, Politeknik Negeri Sriwijaya \\ email: mzaman0284@gmail.com \\ ${ }^{2}$ Sony Oktapriandi, Politeknik Negeri Sriwijaya \\ email: sony.oktapriandi@gmail.com \\ ${ }^{3}$ Nelly Masnila, Politeknik Negeri Sriwijaya \\ email: nilahilal@yahoo.com
}

\begin{abstract}
Kain songket Palembang adalah salah satu hasil kerajinan tenun khas daerah Sumatera Selatan, dikenal dengan nama songket Palembang, dibuat dari bahan dasar benang sutera dan benang mas melalui proses penenunan, merupakan warisan budaya daerah, khususnya Palembang dan Sumatera Selatan pada umumnya. Kain songket Palembang telah dikenal di berbagai daerah kabupaten kota di Indonesia bahkan manca negara diantaranya Malaysia, Brunai Darussalam, Singapura, Jepang serta beberapa konsumen dari Eropa yang sangat berpotensi untuk dapat dikembangkan. Namun dalam hal pemasaran, khususnya pada usaha kecil menengah Tenun Songket Romlah Fauzi mengalami permasalahan tentang manajemen pemasaran, secara tidak langsung berdampak pada peningkatan omset. Salah satu upaya untuk memenuhi peningkatan omset tersebut perlu dilakukan upaya perbaikan manajemen pemasaran. Tujuan Penelitian adalah membantu UKM tenun songket Romlah Fauzi khususnya dalam upaya meningkatkan omset melalui perbaikan pengetahuan tentang manajemen pemasaran. Metode yang diterapkan dengan melakukan perbaikan sistem manajemen pemasaran (promo produk berbasis web) yang diawali dengan kontrol kualitas benang, produk jadi (desain motif), proses produksi. Ruang lingkup penelitian adalah perbaikan manajemen pemasaran melalui keterampilan sumber daya manusia berbasis web dengan tolok ukur peningkatan omset. Hasil penelitian yang telah dilaksanakan (2017) setelah diterapkan perbaikan terhadap manajemen pemasaran berbasis web menunjukkan terjadi peningkatan omset rata-rata sebesar 33,29\% dibandingkan tahun terakhir 2014/2015.
\end{abstract}

Kata Kunci : Mananjemen Pemasaran, Omset, Tenun Songket Palembang. 


\title{
IMPROVEMENT OF MARKETING MANAGEMENT ON INCREASING TURNOVER OF SONGKET PALEMBANG WEAVING PRODUCTS
}

\author{
Muhammad Zaman ${ }^{1)}$, Sony Oktapriandi ${ }^{2)}$, Nelly Masnila ${ }^{3)}$ \\ ${ }^{1}$ Teknik Kimia, Politeknik Negeri Sriwijaya \\ email: mzaman0284@gmail.com \\ ${ }^{2}$ Sony Oktapriandi, Politeknik Negeri Sriwijaya \\ email: sony.oktapriandi@gmail.com \\ ${ }^{3}$ Nelly Masnila, Politeknik Negeri Sriwijaya \\ email: nilahilal@yahoo.com
}

\begin{abstract}
Palembang songket is one of the weaving products typical of South Sumatra, known as the palembang songket, made from basic ingredients of silk thread and yarn through weaving process, is a regional cultural heritage, especially Palembang and South Sumatra in general. Palembang songket fabric has been known in various city districts in Indonesia and even abroad, including Malaysia, Brunei, Singapore, Japan and several European consumers that have the potential to be developed. But in terms of marketing, especially in UKM Songket Weaving Romlah Fauzi experienced problems about marketing management, indirectly impact on increasing turnover. One of the efforts to meet the increase in turnover needs to be done to improve marketing management.

The aim of the research was to help Romlah Fauzi songket weaving small and medium enterprises especially in an effort to increase turnover through improving knowledge of marketing management. The method applied by improving the marketing management system (promo web-based products) which begins with yarn quality control, finished products (motif design), production processes.

The scope of research is the improvement of marketing management through web-based human resource skills with increasing turnover benchmarks.

The results of research carried out (2017) after applying improvements to web-based marketing management showed an increase in average turnover of 33.29\% compared to the last year of 2014/2015.
\end{abstract}

Keywords: Marketing Management, Turnover, Palembang Songket Weaving. 


\section{PENDAHULUAN}

Tenun songket Palembang merupkan salah satu hasil kerajinan tenun khas daerah Sumatera Selatan, dikenal dengan nama songket Palembang, dibuat dari bahan dasar benang sutera dan benang mas, merupakan warisan budaya daerah, khususnya Palembang dan Sumatera Selatan pada umumnya. Tenun songket Palembang telah dikenal di berbagai daerah kabupaten kota di Indonesia bahkan manca negara diantaranya Malaysia, Brunai Darussalam, Singapura, Jepang serta beberapa konsumen dari Eropa. Namun dalam hal pemasaran, khususnya pada UKM Tenun Songket Romlah Fauzi mengalami permasalahan tentang manajemen pemasaran, secara tidak langsung berdampak pada omset. UKM Tenun Songket Romlah Fauzi telah berdiri sejak tahun 2000 hingga tahun 2014 melaksanakan pemasaran produk songket hanya dengan melalui pesanan dan penjualan produk secara langsung ke konsumen tanpa melalui promosi. Produk dapat terjual rata-rata hanya sebanyak 4 set perbulan dengan harga jual produk rata-rata 5 juta rupiah melalui persaingan harga, tercatat sebagai omset saat itu (2014) sebesar Rp 532.425.000,- (Zaman, M, dkk, 2017). Kondisi UKM Tenun Songket Romlah Fauzi berdasarkan penelitian yang dilaksanakan umumnya tidak berjalan lebih baik sebagaimana mestinya, terutama masalah manajemen pemasaran tanpa memahami teknik pemasaran karena kurang memiliki pengetahuan tentang pemasaran, terutama tentang teknik pemasaran online, termasuk belum memiliki production planning, accounting-bookiping, auditing, pola desain produk, kuantitas dan kualitas produk serta manajemen usaha (bahan baku, proses, produksi), sehingga menyebabkan penghasilan omset tidak sesuai dengan harapan. Salah satu upaya untuk memenuhi keinginan produsen dan karyawan perlu dilakukan upaya melaksanakan perbaikan manajemen pemasaran dengan tetap memperhatikan production planning, accounting-bookiping, auditing, pola desain produk, kuantitas dan kualitas produk serta manajemen usaha (bahan baku, proses, produksi). Salah satu upaya untuk memenuhi peningkatan omset dilakukan upaya perbaikan manajemen pemasaran.

\section{IDENTIFIKASI MASALAH}

Sebelum menetapkan ruang lingkup penelitian dilakukan identifikasi dengan mendata kondisi UKM mitra 1 dan 2, sehingga diambil mitra 1 yang memungkinkan untuk dapat ditetapkan sebagai objek penelitian, mengingat pertimbangan terhadap jumlah karyawan dan proses produksi pada mitra 2 kurang optimal untuk ditetapkan sebagai objek. Ruang lingkup penelitian yang ditinjau adalah peningkatan terhadap kuantitas dan kualitas desain motif melalui keterampilan SDM dengan tolok ukur peningkatan omset (jumlah produk yang terjual, omset, rupiah) terhadap waktu (bulan) pada UKM "Hj. Romlah Fauzi" (mitra UKM 1) tahun 2017 (bulan Januari hingga Desember 2017).

\section{METODE PENELITIAN}

Metode yang diterapkan untuk mencapai tujuan dengan melakukan perbaikan sistem manajemen pemasaran yang diawali dengan kontrol kualitas benang, produk jadi (desain motif), proses produksi, keterampi lan SDM dan sebagai metode utama yang diteliti adalah sistem informasi pasar dan pemasaran produk berbasis web. Penelitian dilakukan pada UKM tenun songket palembang "Hj. Romlah Fauzi" (mitra UKM 1), beralamat di Jalan Kiranggo Wiro Sentiko No. 462 RT 12 Kelurahan 30 Ilir Palembang. Bahan baku yang digunakan adalah benang sutera dan benang mas, ditenun menggunakan unit peralatan tenun songket. Lamanya waktu proses penenunan satu set kain 
songket rata-rata dapat ditempuh satu bulan per orang tergantung motif dan kualitas diawali melalui beberapa tahapan kontrol proses produksi: pengawasan pada pengukuran dan pemotongan bahan untuk memastikan sesuai dengan spesifikasi produk yang akan dihasilkan, pengawasan dalam desain motif dan warna benang yang digunakan untuk menghasilkan produk sesuai yang diinginkan, pengawasan dalam proses penenunan dan finishing produk. Teknik analisis data berupa data kuantitatif, diambil dari jumlah dan jenis kain songket yang terjual (rupiah) terhadap waktu (bulan) dicatat setiap minggu yang dirangkum dalam tiap bulan, dimulai pada bulan Januari hingga bulan Desember 2017. Setelah data hasil penjualan dikumpulkan setiap minggu dicatat pada buku harian hingga akhir bulan dirangkum dalam satu bulan yang dicatat sebagai omset. Begitu pula untuk bulan berikutnya dengan cara yang sama pencatatan/pembukuan dilaksanakan setiap minggu kemudian dirangkum setiap bulan berikutnya, dan seterusnya, sehingga pada tabel akan tergambar grafik omset (rupiah) versus waktu (bulan). Variabel penelitian ada 2 (dua) : variabel $\mathrm{X}=$ omset (rupiah) dan variabel $\mathrm{Y}=$ waktu (bulan) dengan mengambil data jumlah kain songket yang terjual (omset) terhadap waktu (bulan). Data diambil setiap minggu yang dirangkum dalam tiap bulan (Januari 2017 hingga Desember 2017).

\section{HASIL DAN PEMBAHASAN}

\subsection{Hasil}

Tabel 1. Omset Bulan Januari 2017

\begin{tabular}{|l|l|l|r|r|r|}
\hline No & \multicolumn{1}{|c|}{ Tanggal } & \multicolumn{1}{c|}{ Uraian } & \multicolumn{1}{c|}{ Kredit } & \multicolumn{1}{c|}{ Debit } & \multicolumn{1}{c|}{ Saldo } \\
\hline 1 & $4-1-2017$ & Songket Motif Cantik Manis & 10000000 & & 10000000 \\
\hline 2 & $6-1-2017$ & Songket Motif Pacar Cina & 7400000 & & 17400000 \\
\hline 3 & $9-1-2017$ & Songket Motif Nampan Perak Bintang & 12600000 & & 30000000 \\
\hline 4 & $12-1-2017$ & Songket Motif Jumputan & 6500000 & & 36500000 \\
\hline 5 & $14-1-2017$ & Songket Motif Biji Pare & 8000000 & & 44500000 \\
\hline 6 & $16-1-2017$ & Songket Motif Bintang Berantai & 3900000 & & 48400000 \\
\hline 7 & $21-1-2017$ & Songket Motif Nampan Perak & 2800000 & & $\mathbf{5 1 2 0 0 0 0 0}$ \\
\hline & & & $\mathbf{5 1 2 0 0 0 0 0}$ \\
\hline
\end{tabular}

Tabel 2. Omset Bulan Februari 2017

\begin{tabular}{|c|c|l|r|r|r|}
\hline No & \multicolumn{1}{|c|}{ Tanggal } & \multicolumn{1}{c|}{ Uraian } & \multicolumn{1}{c|}{ Kredit } & \multicolumn{1}{c|}{ Debit } \\
\hline 1 & $2-2-2017$ & Songket Motif Jumputan & 13000000 & & 13000000 \\
\hline 2 & $5-2-2017$ & Songket Motif Biji Pare & 7400000 & & 20400000 \\
\hline 3 & $7-2-2017$ & Songket Motif Cantik Manis & 14600000 & & 35000000 \\
\hline 4 & $8-2-2017$ & Songket Motif Pacar Cina & 6500000 & & 41500000 \\
\hline 5 & $12-2-2017$ & Songket Motif Nampan Perak Bintang & 7500000 & & 49000000 \\
\hline 6 & $17-2-2017$ & Songket Motif Bintang Berantai & 3900000 & & 52900000 \\
\hline 7 & $23-2-2017$ & Songket Motif Nampan Perak & 4600000 & & $\mathbf{5 7 5 0 0 0 0 0}$ \\
\hline \multicolumn{7}{|l|}{} \\
\hline
\end{tabular}

Tabel 3. Omset Bulan Maret 2017

\begin{tabular}{|c|c|l|r|r|r|}
\hline No & \multicolumn{1}{|c|}{ Tanggal } & \multicolumn{1}{c|}{ Uraian } & \multicolumn{1}{c|}{ Dedit } & \multicolumn{1}{c|}{ Saldo } \\
\hline 1 & $1-3-2017$ & Songket Motif Nampan Perak Bintang & 13500000 & & 13500000 \\
\hline 2 & $3-3-2017$ & Songket Motif Jumputan & 7400000 & & 20900000 \\
\hline 3 & $7-3-2017$ & Songket Motif Biji Pare & 12600000 & & 33500000 \\
\hline 4 & $9-3-2017$ & Songket Motif Bintang Berantai & 9500000 & & 43000000 \\
\hline
\end{tabular}




\begin{tabular}{|l|l|l|r|r|r|}
\hline 5 & $10-3-2017$ & Songket Motif Nampan Perak & 7800000 & & 50800000 \\
\hline 6 & $14-3-2017$ & Songket Motif Cantik Manis & 3800000 & & 54600000 \\
\hline 7 & $17-3-2017$ & Songket Motif Pacar Cina & 2800000 & & $\mathbf{5 7 4 0 0 0 0 0}$ \\
\hline & & \multicolumn{5}{|l|}{ Omset } & $\mathbf{5 7 4 0 0 0 0 0}$ \\
\hline
\end{tabular}

Tabel 4. Omset Bulan April 2017

\begin{tabular}{|c|c|l|r|r|r|}
\hline No & \multicolumn{1}{|c|}{ Tanggal } & \multicolumn{1}{c|}{ Uraian } & \multicolumn{1}{c|}{ Kredit } & \multicolumn{1}{c|}{ Debit } & \multicolumn{1}{c|}{} \\
\hline 1 & $2-4-2017$ & Songket Motif Bintang Berantai & 12000000 & & 12000000 \\
\hline 2 & $5-4-2017$ & Songket Motif Nampan Perak & 7400000 & & 35000000 \\
\hline 3 & $6-4-2017$ & Songket Motif Cantik Manis & 15600000 & & 41500000 \\
\hline 4 & $8-4-2017$ & Songket Motif Pacar Cina & 6500000 & & 49300000 \\
\hline 5 & $11-4-2017$ & Songket Motif Nampan Perak Bintang & 7800000 & & 53200000 \\
\hline 6 & $16-4-2017$ & Songket Motif Jumputan & 3900000 & & $\mathbf{5 6 0 0 0 0 0 0}$ \\
\hline 7 & $20-4-2017$ & Songket Motif Biji Pare & 2800000 & & $\mathbf{5 6 0 0 0 0 0 0}$ \\
\hline
\end{tabular}

Tabel 5. Omset Bulan Mei 2017

\begin{tabular}{|l|l|l|l|l|l|}
\hline No & Tanggal & \multicolumn{1}{c|}{ Uraian } & Kredit & Debit & \multicolumn{1}{c|}{ Saldo } \\
\hline 1 & $1-5-2017$ & Songket Motif Bintang Berantai & 13000000 & & 13000000 \\
\hline 2 & $5-5-2017$ & Songket Motif Nampan Perak & 11700000 & & 24700000 \\
\hline 3 & $6-5-2017$ & Songket Motif Cantik Manis & 14300000 & & 39000000 \\
\hline 4 & $8-5-2017$ & Songket Motif Pacar Cina & 6500000 & & 45500000 \\
\hline 5 & $10-5-2017$ & Songket Motif Nampan Perak Bintang & 7800000 & & 53300000 \\
\hline 6 & $13-5-2017$ & Songket Motif Jumputan & 3900000 & & 57200000 \\
\hline 7 & $18-5-2017$ & Songket Motif Biji Pare & 8800000 & & $\mathbf{6 6 0 0 0 0 0 0}$ \\
\hline & \multicolumn{3}{|l|}{} & Omset & $\mathbf{6 6 0 0 0 0 0 0}$ \\
\hline
\end{tabular}

Tabel 6. Omset Bulan Juni 2017

\begin{tabular}{|l|l|l|l|l|l|}
\hline No & \multicolumn{1}{|c|}{ Tanggal } & \multicolumn{1}{c|}{ Uraian } & Kredit & Debit & Saldo \\
\hline 1 & $2-6-2017$ & Songket Motif Bintang Berantai & 16000000 & & 16000000 \\
\hline 2 & $5-6-2017$ & Songket Motif Nampan Perak & 16700000 & & 32700000 \\
\hline 3 & $6-6-2017$ & Songket Motif Cantik Manis & 6300000 & & 39000000 \\
\hline 4 & $8-6-2017$ & Songket Motif Pacar Cina & 6500000 & & 45500000 \\
\hline 5 & $11-6-2017$ & Songket Motif Nampan Perak Bintang & 7800000 & & 53300000 \\
\hline 6 & $15-6-2017$ & Songket Motif Jumputan & 4000000 & & 57300000 \\
\hline 7 & $20-6-2017$ & Songket Motif Biji Pare & 9700000 & & $\mathbf{6 7 0 0 0 0 0 0}$ \\
\hline & \multicolumn{3}{|l|}{} & Omset & $\mathbf{6 7 0 0 0 0 0 0}$ \\
\hline
\end{tabular}

Tabel 7. Omset Bulan Juli 2017

\begin{tabular}{|l|l|l|r|r|r|}
\hline No & Tanggal & \multicolumn{1}{c|}{ Uraian } & Kredit & Debit & \multicolumn{1}{c|}{ Saldo } \\
\hline 1 & $1-7-2017$ & Songket Motif Bintang Berantai & 14000000 & & 14000000 \\
\hline 2 & $5-7-2017$ & Songket Motif Nampan Perak & 16700000 & & 30700000 \\
\hline 3 & $6-7-2017$ & Songket Motif Biji Pare & 6300000 & & 37000000 \\
\hline 4 & $8-7-2017$ & Songket Motif Pacar Cina & 6500000 & & 43500000 \\
\hline 5 & $12-7-2017$ & Songket Motif Nampan Perak Bintang & 7800000 & & 51300000 \\
\hline 6 & $15-7-2017$ & Songket Motif Jumputan & 4000000 & & 55300000 \\
\hline 7 & $17-7-2017$ & Songket Motif Cantik Manis & 9700000 & & $\mathbf{6 5 0 0 0 0 0 0}$ \\
\hline & \multicolumn{3}{|c|}{} & Omset & $\mathbf{6 5 0 0 0 0 0}$ \\
\hline
\end{tabular}

Tabel 8. Omset Bulan Agustus 2017

\begin{tabular}{|l|c|c|l|l|c|}
\hline No & Tanggal & Uraian & Kredit & Debit & Saldo \\
\hline 1 & $1-8-2017$ & Songket Motif Jumputan & 10000000 & & 10000000 \\
\hline
\end{tabular}




\begin{tabular}{|l|l|l|r|r|r|}
\hline 2 & $4-8-2017$ & Songket Motif Nampan Perak & 11700000 & & 21700000 \\
\hline 3 & $7-8-2017$ & Songket Motif Cantik Manis & 14300000 & & 36000000 \\
\hline 4 & $9-8-2017$ & Songket Motif Biji Pare & 6500000 & & 42500000 \\
\hline 5 & $10-8-2017$ & Songket Motif Bintang Berantai & 7800000 & & 50300000 \\
\hline 6 & $12-8-2017$ & Songket Motif Pacar Cina & 3900000 & & 54200000 \\
\hline 7 & $15-8-2017$ & Songket Motif Nampan Perak Bintang & 7800000 & & $\mathbf{6 2 0 0 0 0 0 0}$ \\
\hline & \multicolumn{3}{|c|}{ Omset } & $\mathbf{6 2 0 0 0 0 0 0}$ \\
\hline
\end{tabular}

Tabel 9. Omset Bulan September 2017

\begin{tabular}{|l|r|l|r|r|r|}
\hline No & Tanggal & \multicolumn{1}{c|}{ Uraian } & \multicolumn{1}{c|}{ Kredit } & \multicolumn{1}{c|}{ Debit } & \multicolumn{1}{l|}{ Saldo } \\
\hline 1 & $2-9-2017$ & Songket Motif Bintang Berantai & 11000000 & & 11000000 \\
\hline 2 & $5-9-2017$ & Songket Motif Nampan Perak & 7400000 & & 18400000 \\
\hline 3 & $7-9-2017$ & Songket Motif Cantik Manis & 16600000 & & 35000000 \\
\hline 4 & $9-9-2017$ & Songket Motif Pacar Cina & 6500000 & & 41500000 \\
\hline 5 & $10-9-2017$ & Songket Motif Nampan Perak Bintang & 7800000 & & 49300000 \\
\hline 6 & $17-9-2017$ & Songket Motif Jumputan & 3900000 & & 53200000 \\
\hline 7 & $20-9-2017$ & Songket Motif Biji Pare & 2800000 & & $\mathbf{5 6 0 0 0 0 0 0}$ \\
\hline & & \multicolumn{5}{|l|}{} & Omset & $\mathbf{5 6 0 0 0 0 0 0}$ \\
\hline
\end{tabular}

Tabel 10. Omset Bulan Oktober 2017

\begin{tabular}{|l|r|l|r|r|r|}
\hline No & \multicolumn{1}{|c|}{ Tanggal } & \multicolumn{1}{c|}{ Uraian } & \multicolumn{1}{c|}{ Debit } & \multicolumn{1}{c|}{ Saldo } \\
\hline 1 & $2-10-2017$ & Songket Motif Bintang Berantai & 12000000 & & 12000000 \\
\hline 2 & $6-10-2017$ & Songket Motif Nampan Perak & 7400000 & & 19400000 \\
\hline 3 & $7-10-2017$ & Songket Motif Cantik Manis & 15600000 & & 35000000 \\
\hline 4 & $9-10-2017$ & Songket Motif Pacar Cina & 6500000 & & 41500000 \\
\hline 5 & $10-10-2017$ & Songket Motif Nampan Perak Bintang & 7800000 & & 49300000 \\
\hline 6 & $12-10-2017$ & Songket Motif Jumputan & 3900000 & & 53200000 \\
\hline 7 & $16-10-2017$ & Songket Motif Biji Pare & 2700000 & & $\mathbf{5 5 9 0 0 0 0 0}$ \\
\hline & & \multicolumn{5}{|c|}{ Omset } & $\mathbf{5 5 0 0 0 0}$ \\
\hline
\end{tabular}

Tabel 11. Omset Bulan November 2017

\begin{tabular}{|l|l|l|r|r|r|}
\hline No & \multicolumn{1}{|c|}{ Tanggal } & \multicolumn{1}{|c|}{ Uraian } & Kredit & \multicolumn{1}{c|}{ Debit } & \multicolumn{1}{c|}{ Saldo } \\
\hline 1 & $1-11-2017$ & Songket Motif Bintang Berantai & 14000000 & & 14000000 \\
\hline 2 & $5-11-2017$ & Songket Motif Nampan Perak & 16700000 & & 30700000 \\
\hline 3 & $6-11-2017$ & Songket Motif Biji Pare & 6300000 & & 37000000 \\
\hline 4 & $8-11-2017$ & Songket Motif Pacar Cina & 6500000 & & 43500000 \\
\hline 5 & $12-11-2017$ & Songket Motif Nampan Perak Bintang & 7800000 & & 51300000 \\
\hline 6 & $15-11-2017$ & Songket Motif Jumputan & 4000000 & & 55300000 \\
\hline 7 & $17-11-2017$ & Songket Motif Cantik Manis & 9700000 & & $\mathbf{6 5 0 0 0 0 0 0}$ \\
\hline & \multicolumn{3}{|l|}{} & Omset & $\mathbf{6 5 0 0 0 0 0 0}$ \\
\hline
\end{tabular}

Tabel 12. Omset Bulan Desember 2017

\begin{tabular}{|c|c|l|r|r|r|}
\hline No & \multicolumn{1}{|c|}{ Tanggal } & \multicolumn{1}{c|}{ Uraian } & Kredit & Debit & \multicolumn{1}{c|}{ Saldo } \\
\hline 1 & $1-12-2017$ & Songket Motif Jumputan & 10000000 & & 10000000 \\
\hline 2 & $7-12-2017$ & Songket Motif Cantik Manis & 14300000 & & 24300000 \\
\hline 3 & $9-12-2017$ & Songket Motif Biji Pare & 6500000 & & 30800000 \\
\hline 4 & $10-12-2017$ & Songket Motif Bintang Berantai & 7800000 & & 38600000 \\
\hline 5 & $12-12-2017$ & Songket Motif Pacar Cina & 4200000 & & 42800000 \\
\hline 6 & $15-12-2017$ & Songket Motif Nampan Perak Bintang & 7900000 & & $\mathbf{5 0 7 0 0 0 0 0}$ \\
\hline & \multicolumn{3}{|l|}{} & Omset & $\mathbf{5 0 7 0 0 0 0 0}$ \\
\hline
\end{tabular}


Tabel 13. Rekap Omset UKM Romlah Fauzi 2017

\begin{tabular}{|c|c|c|}
\hline No & Bulan-Tahun & Omset (Rp) \\
\hline 1 & Januari-2017 & 51200000 \\
\hline 2 & Februari-2017 & 57500000 \\
\hline 3 & Maret-2017 & 57400000 \\
\hline 4 & April-2017 & 56000000 \\
\hline 5 & Mei-2017 & 66000000 \\
\hline 6 & Juni-2017 & 67000000 \\
\hline 7 & Juli-2017 & 65000000 \\
\hline 8 & Agustus-2017 & 62000000 \\
\hline 9 & September-2017 & 56000000 \\
\hline 10 & Oktober-2017 & 55900000 \\
\hline 11 & November-2017 & 65000000 \\
\hline 12 & Desember-2017 & 50700000 \\
\hline \multicolumn{2}{|r|}{ Jumlah } & 709700000 \\
\hline
\end{tabular}

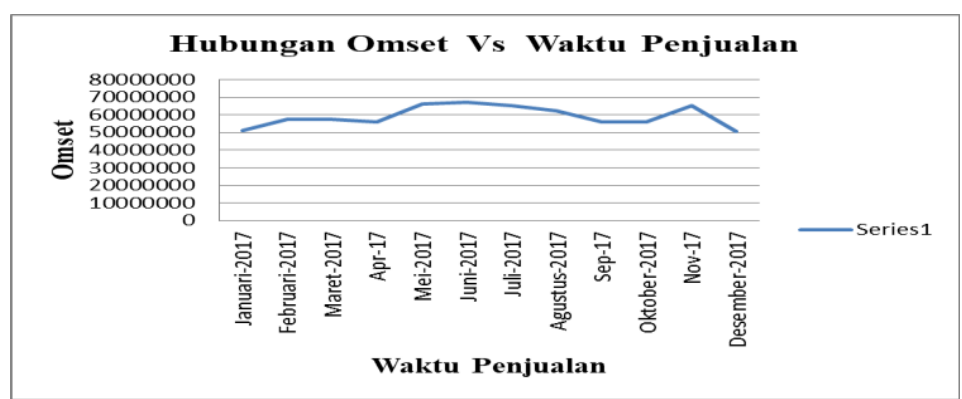

Gambar Grafik : Hubungan Omset (rupiah) Terhadap Waktu (bulan)

\subsection{Pembahasan}

Pada gambar grafik menunjukkan hubungan omset (rupiah) terhadap waktu (bulan), dimana omset terkecil terjadi pada bulan Desember 2017 sebesar Rp 50.700.000,- dan omset terbesar pada bulan Juni 2017 sebesar Rp 67.000.000,- . Kisaran omset antara Rp 50.700.000 sampai Rp 67.000.000 perbulan, dengan total omset sebesar Rp 709.700.000,- per tahun (cash flow) atau rata-rata sebesar Rp 59.141.666,- per bulan. Berdasarkan data hasil penelitian tersebut, kecilnya omset terjadi pada bulan desember 2017 dikarenakan berkurangnya transaksi penjualan menjelang tahun baru, namun bila dibandingkan beberapa tahun sebelumnya 2014/2015 omset masih jauh lebih besar pada bulan yang sama desember. Omset terbesar justru terjadi pada bulan juni menjelang lebaran
2017. Adanya peningkatan omset tersebut disebabkan adanya upaya perbaikan terhadap manajemen pemasaran yang dilakukan menggunakan website (pasar online) dengan pendampingan melalui penerapan Iptek sebagai implementasi Program Pengembangan Produk Ekspor pada UKM mitra 1 (UKM Tenun Songket Romlah Fauzi).

\section{KESIMPULAN}

Dari tabel data omset dalam 12 bulan (JanuariDesember 2017) yang ditunjukkan pada grafik hubungan omset (rupiah) terhadap waktu penjualan (bulan) terjadi peningkatan yang cukup baik hingga mencapai sebesar Rp 709.700.000 yang sebelumnya sebesar Rp 532.425 .000 pada tahun 2014/2015, yang berarti terjadi peningkatan sebesar $33,29 \%$ 
dibandingkan tahun sebelumnya 2014/2015. Adanya peningkatan omset tersebut antara lain disebabkan adanya upaya perbaikan terhadap manajemen pemasaran yang dilakukan menggunakan website (pasar online) dengan pendampingan melalui penerapan Iptek sebagai implementasi Program Pengembangan Produk Ekspor pada UKM mitra 1 (UKM Tenun Songket Romlah Fauzi).

\section{UCAPAN TERIMAKASIH}

Ucapan terimakasih ditujukan kepada semua pihak yang membantu proses penyusunan, termasuk beberapa masukan yang kami terima dalam menyelesaikan artikel tersebut, baik dari literatur maupun masyarakat kampus serta masyarakat UKM, khususnya kepada tim penerbit artikel APTEKMAS Politeknik Negeri Sriwijaya.

\section{REFERENSI}

------, "Persyaratan Pokok Seorang

Pengusaha Handal Dan Kualifikasi

Wirausaha Unggul", 1996, Departemen Koperasi dan Pembinaan Pengusaha Kecil Kotamadya Palembang.

-------, "Makalah Penataran Manajemen Mutu Terpadu", 1995,Universitas Sriwijaya, Palembang .

Badan Standardisasi Nasional, 2013, Sistem Manajemen Mutu SNI ISO 9001:2008, Penerapan pada UKM, Oleh Badan Standardisasi Nasional, Jakarta.

Bank Indonesia, 1999, "Materi Pelatihan Unit Pengembangan Usaha Kecil Menengah Untuk Penyusunan Laporan Permohonan Kredit, Proyek Pengembangan Usaha Kecil (SEDP V), Jakarta.

Grant, Eugene L., 1987, "Dasar-Dasar Ekonomi Teknik", Penerbit : PT. Bina Aksara, Jakarta.

Hasyim Z, A, 1996, "Modul Pelatihan Kewirausahaan”, Palembang.

Ishikawa, K., David J, 1987, "Pengendalian
Mutu Terpadu", Penerbit : Ramadja Karya CV, Bandung.

Jusup Haryono, 1997, "Praktik Akuntansi", edisi pertama, Pusat Penerbit Akademik Akuntansi YKPN., Yogyakarta.

Mursid, M. 1993, “Manajemen Pemasaran”, Penerbit : Bumi Aksara, Jakarta.

Zaman, M. 2006, Vucer Multi Tahun, Program DP2M Dikti, "Laporan Penerapan Iptek untuk Meningkatkan Kualitas dan Kuantitas Produk Meubel Palembang", Politeknik Negeri Sriwijaya. Palembang.

Zaman, M. 2017, Program Multi Tahun DRPM Dikti, "Laporan Program Pengembangan Produk Ekspor", Politeknik Negeri Sriwijaya. Palembang. 